\title{
Uterine Corpus Leiomyosarcoma and Endometrial Stromal Sarcoma Pathologic Distant Metastasis TNM Finding v8
}

National Cancer Institute

\section{Source}

National Cancer Institute. Uterine Corpus Leiomyosarcoma and Endometrial Stromal

Sarcoma Pathologic Distant Metastasis TNM Finding v8. NCI Thesaurus. Code C139822.

A pathologic finding about one or more characteristics of uterine corpus

leiomyosarcoma or endometrial stromal sarcoma, following the rules of the TNM AJCC

v8 classification system as they pertain to distant metastases. 